\title{
SCP Paradigm Analysis and Countermeasures of China's Automobile Industry
}

\author{
Mengchun Ding, Dan Wang \& Ying Wang \\ Changchun University of Science and Technology, Changchun 130022, China \\ E-mail: dingmengchun312@163.com
}

Received: December 26, 2010

Accepted: January 26, 2011

doi:10.5539/jsd.v4n2p211

\begin{abstract}
China's automobile industry has made great progress and contributed a lot to national economic development, but the problems such as dispersion, small, disorderly, worse" in the industry is still very serious. Starting from the SCP paradigm theory in China's automobile industry, the article analyses the problems including the market structure, market conduct and market performance in China's automobile industry and corresponding conclusions are drawn. Then the authors analyze the reasons for the current situation of China's automobile industry and provide reference for the recombination of China's automobile industry, and finally the countermeasures are proposed to promote reorganization and integration.
\end{abstract}

Keywords: SCP paradigm, Recombination, Integration

\section{SCP paradigm analysis of China's automobile industry}

SCP paradigm analysis is the mainstream in the theory system of industry organization, which includes three categories as follows: market structure, market conduct and market performance, namely, structure-conduct-performance paradigm. It mainly studies the influence of market structure such as market concentration rate, product differentiation and entry barriers on market conduct such as corporate price, output, production cost, sale cost and product design, and evaluates market recourse allocation performance. In their relationship, market structure determines market conduct and market conduct determines market performance.

\subsection{The analysis of market structure in China's automobile industry}

Market structure is a concept that reflects the relationship between market competition and monopoly, which is often defined as the characteristics and forms that make a difference on the degree of competition and price formation in the market. The major factors that determines market structure includes: market concentration rate, product differentiation and the level of the entry and exit barriers.

\subsubsection{Market concentration}

Market concentration rate is an indicator which is used to measure the relatively scale structure of an enterprise in specific industry or market. It includes absolute concentration rate index and relative concentration rate index, and the article adopts absolute concentration rate index.

Absolute concentration rate is generally shown by the ratio between the accumulated quantity or amount of production, sale, assets and staff in the first several enterprises (Usually the top 4 or top 8 ) in terms of scale and that of production, sale, assets and staff in the total market. Its calculation formula is:

$$
C R_{n}=\sum_{i=1}^{n} X_{i} / \sum_{i=1}^{N} X_{i}
$$

$C R_{n}$ represents the market concentration rate of the first several enterprises with largest scale in the industry $X$, and represents the sum of production, sale, assets or staff in $n$ enterprises. $X_{i}$ represents the production, sale, assets and staff number of the enterprise ranked $i$ in the industry $X . N$ represents the total number of enterprises in the industry $X$.

According to the formula above, combined with corresponding data, the situations of market concentration rate of China's automobile industry in recent years is obtained as shown in table 1. From the table 1, we can see the market concentration rate of the top 4 and top 8 enterprises in China's automobile industry is increasing continuously. According to the classification about the type of industrial monopoly and competition by Bain in table 2, the market concentration rate of China's automobile industry reached $82.2 \%$ in 2009 , which belongs to 
medium (Upper) oligopoly type industry. The market concentration rate of automobile industry in developed countries such as America, Japan and Europe belongs to very high concentration oligopoly type.

\subsubsection{Product differentiation}

Product differentiation is the different preferences to the similar product produced by different enterprises in the same industry. The preferences sources from the differentiations in the aspect of quality, design, performance, the ignorance of customers about the product characteristics they purchase and customers' preference to certain product caused by the sales method such as advertisement. Generally speaking, the more the differentiation is, the higher the specialization degree is, and then this product has advantages compared with other similar products. Automobile industry belongs to durable customer goods industry, whose products should have very high product differentiation, mainly in the aspect of product physical characteristics.

In recent years, domestic automobile industry expands rapidly, which lead to the insufficient investment in research and development inevitably. Finally more China's brand automobiles imitate the appearance of foreign luxury brand. As a whole, China's automobile product differentiation lags behind developed countries.

\subsubsection{Entry and Exit barriers}

When a new enterprise enters certain industry, it will encounter a great deal of adverse factors relative to the incumbent. The obstacles or the adverse factors that hinder a new enterprise enter are called enter barriers. The factors which forms enter barriers include mainly: scale economy, requisite capital barriers and policy and law.

1) Scale economy

Up to 2009, there are still 168 vehicle manufacturers in China. Among the top 10 enterprises, eight enterprises exceed 400,000 and eight enterprises exceed 600,000. The scale of automobile enterprises in China is small generally, a large number of enterprises have not reached the requirements of the primary scale economy, but the continuous expansion and increase of automobile market still can make them gain high profits.

2) Requisite capital barriers

Requisite capital barriers are the necessary capital that a new enterprise must invest when entering the market. Generally, the capital scale of vehicle project is over 10 billion. In China, the financial system is imperfect, which provides limited channel for automobile enterprises, so requisite capital barriers of automobile enterprise is higher.

\section{3) Policy and law barriers}

Exit barriers mean some factors that organize enterprise to exit market. The exit barriers of automobile industry in China is very high: Firstly, the high investment in the equipments of automobile industry and their specificity lead to high sunk cost in enterprises, meanwhile, information asymmetry leads automobile enterprises to pay high switching cost when they exit the industry. Secondly, automobile industry belongs to a pillar industry in China and is protected by government, even though some enterprises cannot sustain because of low profits, the government still support their inefficient operation.

\subsection{The analysis of market conduct in China's automobile industry}

\subsection{1 the investment in research and development}

According to the news published by the department of UK business, innovation and skills, among the top 1000 enterprises which invest in research and development in 2009 globally, there are 20 vehicle manufacturers and 49 auto parts(including tyres) manufacturers. Dongfeng automobile, as the only Chinese enterprise, just invested 147 billion, accounting for $2.1 \%$ of the gross sales. Compared with Europe, US and Japan, there is a large gap in the investment. Research and development capacity is the core competence of automobile enterprise, and one of the key factors whether China's automobile enterprises has competence in the international market.

\subsubsection{Advertisement}

Marketing has decided the success or failure of an enterprise to some degree. In order to prompt sales, automobile enterprises make great effect on the aspect of advertisement and they make use of advertisement for image dissemination and promotion penetration.

With the transition of China's automobile industry from sellers' market to buyer's market, advertisement plays a bigger and bigger role in prompting products sales and improving corporate profits. From figure 1 we can see that the investment in advertisement in China's automobile enterprises is increasing continuously, which also shows there is excessive competition in China's automobile industry. 


\subsubsection{Price behavior}

In order to seize market shares, China's automobile enterprises adopt to all kinds of measures such as price, service and products, but the result of competition is always that the price is dropping continually. In addition, the decrease of labor productivity, Operating costs and financial costs in automobile enterprises make the production cost per piece of products reduce continually, which also provide certain space for the reduction of price. And taking the initiative to price is also the main marketing strategy for the transition of auto type and seizing market shares in automobile enterprises.

\subsection{The analysis of market performance in China's automobile industry}

Market performances are the final results in the aspects including type, price, cost, quality, output, profit and technological progress of the product formed by certain market conduct under certain market structure. China's automobile industry has made great progress on the production and sales, quality, research and development from the beginning in 1950s until now. To the end of 2009, China exceeded America for the first time and became biggest automobile industry country in the world. But the profit of automobile industry in China is very low compared with international standards. From the figure 2 we can see, except that the profit declined greatly in 2005 , the profit of automobile industry has shown a relatively fast trend of growth in recent years. But according to corresponding data statistics, the rapid increase of profit is resulted from the contributions of such large corporate groups as FAW, SAIC and Dongfeng while the profit in some small enterprises are very low.

\section{The analysis of the factors that form the current situations of automobile industry}

Through the analysis of SCP paradigm of automobile industry in China, the article draws the conclusion as follows: at the present stage, the market concentration rate of China's automobile industry is not high enough, far away from scale economy effect, and the industrial entry and exit barriers of are very high, as well as insufficient investment in research and development and low product differentiation make the competition of products has to adopt to the measure of price competition so that the profit of the industry is kept at a low level. The factors that form the current situations of automobile industry are as follows:

\section{1 policy factor}

Automobile industry is a pillar industry in China. In order to prompt the development of the industry, China has taken some measures, for example, strengthen the examination and approval of investment, strict industry entry, with the purpose of improving industry concentration rate and support several large groups to improve competence, but the measures violate market economy rules and the effect is not obvious. Meanwhile, local government implements very closed regional automobile industry plan for their own interests to support local auto enterprises, together with various measures to limit the flow of the products from external district, which inevitably leads to unreasonable allocation of resources and the inefficiency and high cost of enterprises, not conductive for enterprises to carry out international competition.

\subsection{Market factor}

With the continuous increase of economy, residents' purchasing power for automobile increases continually, as well as the capacity of the market of automobile and the number of enterprises. New enterprises enter the industry ceaselessly driven by interests. Even they haven't reached the minimum scale requirements, there are still interests. New and small enterprises can influence the entire benefit of the industry. Integration and reorganization of automobile industry is beneficial to change the market structure of automobile industry, improve its profits, make the enterprises become bigger and stronger and enhance international competition ability.

\section{The countermeasures of integration and reorganization for automobile industry in China}

\subsection{Adopt to different integration modes for automobile enterprises with different scales}

For the top three automobile groups such as FAW, SAIC, Dongfeng in production and sales volume in China, by 2009 , only FAW realized that the sales volume exceeds 2 million and achieved output of economic scale. For large automobile group, on the one hand, adopting to the mode of horizontal integration in industry chain according to the strategy of complementary advantages to expand market shares and reach scale economy. For example, in 2007, the recombination of SAIC with the Southern steam made up its short board in commercial vehicle. The case is a good reference for the recombination of large automobile groups in the future. On the other hand, taking the mode of vertical integration internalizes the market cost, reduces automobile manufacturers' reliance on raw materials suppliers in the upstream and retailers in the downstream, improves the collaborative effect, reduces the cost of information search and transaction, and improve profits. 
For the independent brand automobile enterprises with certain scale in China, regional integration modes induced by government should be adopted. The aim of regional integration for automobile industry is to make most idle stock of resources in inefficient enterprises flow into other enterprises which is short of resources with better operation benefit and development perspective. On the way, the industry structure and resources utilization efficiency in the region are optimized so as to improve entire profit.

\subsection{Strengthen multiaspects of cooperation with transnational automobile enterprises}

The rapid development of China's automobile industry cannot do without the promotion of foreign companies and fund. But relying more on foreign enterprises is not beneficial to the development of China's independent brand automobile enterprises, while current situations of domestic automobile industry require continue to cooperate with transnational enterprises. Firstly, the leading transnational automobile groups have very good brand reputation and advanced technology development and research capacity. If domestic enterprises cooperate with them, the cost of brand modeling and learning can be reduced to some degree. Secondly, the introduction of advanced management experiences especially specialization divide work and cooperation experiences in transnational enterprises, can better reform domestic corporate organization structure. Thirdly, the cooperation with transnational enterprises is conductive to the adjustment and perfection of interior property right structure in Chinese enterprises.

\subsection{Make use of capital market to promote integration}

At this stage, China's securities and financial market has taken shape and several automobile enterprises have solved the problems of financing and reforming successfully through capital market. Part of automobile enterprises have been listed on capital markets at home and abroad and realize integration through securities business. With the continuous development of national economy and mature of capital market, it has become a trend that realize merger and restructure through cross-shareholding of enterprises. Financing with the help of capital market is also beneficial for new enterprises to enter automobile industry.

China's automobile industry has obtained rapid development, but it still in the growth stage now. Under the backgrounds of economics globalization, its competitive ability seems weaker. At this stage, China published policy to encourage automobile to merger and integration, in order to realize scale economy and enhance competitive ability, but it cannot be expanded blindly. To realize scale output doesn't mean to realize scale economy. So for China's integration in automobile industry, large corporate groups adopt to the mode of industry chain integration based on complementary advantages, media corporate groups adopt to the mode of regional integration induced by government according to the principle of 'first and stronger, after the bigger' and 'first specialization, then diversification' to build automobile corporate group with international competitive ability.

\section{References}

Lin, Ruixin. (2010). Correlation analysis of China's industry concentration and profits. Oriental enterprise culture. 2010(4).

Lei, Linsong. (2009). Influence of global financial crisis on China's automobile industry. Auto industry research. 2009(5).

Wang, Tao \& Zhang, Youqin. (2008). Globalization and recombination analysis on international automobile industry. Auto industry research. 2008(7).

Wuyong. (2010). Acquisition and Reorganization - the only way for China's automobile industry to become bigger and stronger. AUTOMOBILE MAINTENANCE. 2010(4).

Wang, Junsong \& He, Canfei. (2009). Agglomeration Economics, FDI Spillovers and Chinese Automobile Enterprises Efficiency. PROGRESS IN GEOGRAPHY. 2009(5).

Zhang, Wenbo \& Chen, hongyan. (2006). Statistical analysis of practical data and the application of SPSS 13.0. People's Post and Telecommunication Publishing House.

Table 1. The situation of market concentration rate of China's automobile industry from 2007 to 2009

\begin{tabular}{|l|l|l|l|}
\hline Year & 2007 & 2008 & 2009 \\
\hline$C R_{4}$ & 56.69 & 58.3 & 61.69 \\
\hline$C R_{8}$ & 78.18 & 79.19 & 82.2 \\
\hline
\end{tabular}

Data source: Obtained through data published by China Auto Industrial Association 
Table 2. The classification about the type of industrial monopoly and competition by Bain

\begin{tabular}{|c|c|c|c|}
\hline type & $\begin{array}{c}\text { Market share of the top } 4 \\
\text { enterprises }\left(C R_{4}\right)\end{array}$ & $\begin{array}{c}\text { Market share of the } \\
\text { top } 8 \\
\text { enterprises }\left(C R_{8}\right)\end{array}$ & $\begin{array}{c}\text { The total number } \\
\text { of enterprises in the } \\
\text { industry }\end{array}$ \\
\hline $\begin{array}{c}\text { very high } \\
\text { concentration } \\
\text { oligopoly(A) type }\end{array}$ & $>75 \%$ & & $<20$ \\
\hline $\begin{array}{c}\text { very high } \\
\text { concentration } \\
\text { oligopoly(B) type }\end{array}$ & $>75 \%$ & $>85 \%$ & $20 \sim 40$ \\
\hline $\begin{array}{c}\text { high concentration } \\
\text { oligopoly type }\end{array}$ & $65 \% \sim 75 \%$ & $75 \% \sim 85 \%$ & $\begin{array}{c}\text { The number of the } \\
\text { enterprises is very } \\
\text { large }\end{array}$ \\
\hline $\begin{array}{c}\text { medium (Upper) } \\
\text { concentration } \\
\text { oligopoly type }\end{array}$ & $50 \% \sim 65 \%$ & $45 \% \sim 75 \%$ & $\begin{array}{c}\text { The number of the } \\
\text { enterprises is very } \\
\text { large }\end{array}$ \\
\hline $\begin{array}{c}\text { medium (lower) } \\
\text { concentration } \\
\text { oligopoly type }\end{array}$ & $35 \% \sim 50 \%$ & $40 \% \sim 45 \%$ & $\begin{array}{c}\text { The number of the } \\
\text { enterprises is very } \\
\text { large }\end{array}$ \\
\hline $\begin{array}{c}\text { low concentration } \\
\text { oligopoly type }\end{array}$ & $30 \% \sim 35 \%$ & & \\
\hline
\end{tabular}

Source from: Yang, Gongpu \& Xia, Dawei. Industry Economics Course.

Table 3. the investment in research and development in China's automobile industry between 2000 and 2008

\begin{tabular}{|c|c|c|c|}
\hline Year & $\begin{array}{c}\text { the expenditure of research and } \\
\text { development } \\
\text { appropriation(A)billion Yuan }\end{array}$ & $\begin{array}{c}\text { Sales revenue (B)billion } \\
\text { Yuan }\end{array}$ & R=A/B(\%) \\
\hline 2000 & 67.7 & 3560.4 & 1.9 \\
\hline 2001 & 58.6 & 4253.7 & 1.38 \\
\hline 2002 & 86.2 & 5947.7 & 1.45 \\
\hline 2003 & 107.3 & 8144.1 & 1.32 \\
\hline 2004 & 129.5 & 9134.3 & 1.42 \\
\hline 2005 & 167.8 & 10108.4 & 1.66 \\
\hline 2006 & 244.7 & 13818.9 & 1.77 \\
\hline 2007 & 308.8 & 17201.4 & 1.8 \\
\hline
\end{tabular}

Data source: Year Book of Automobile industry between 2000 and 2008 


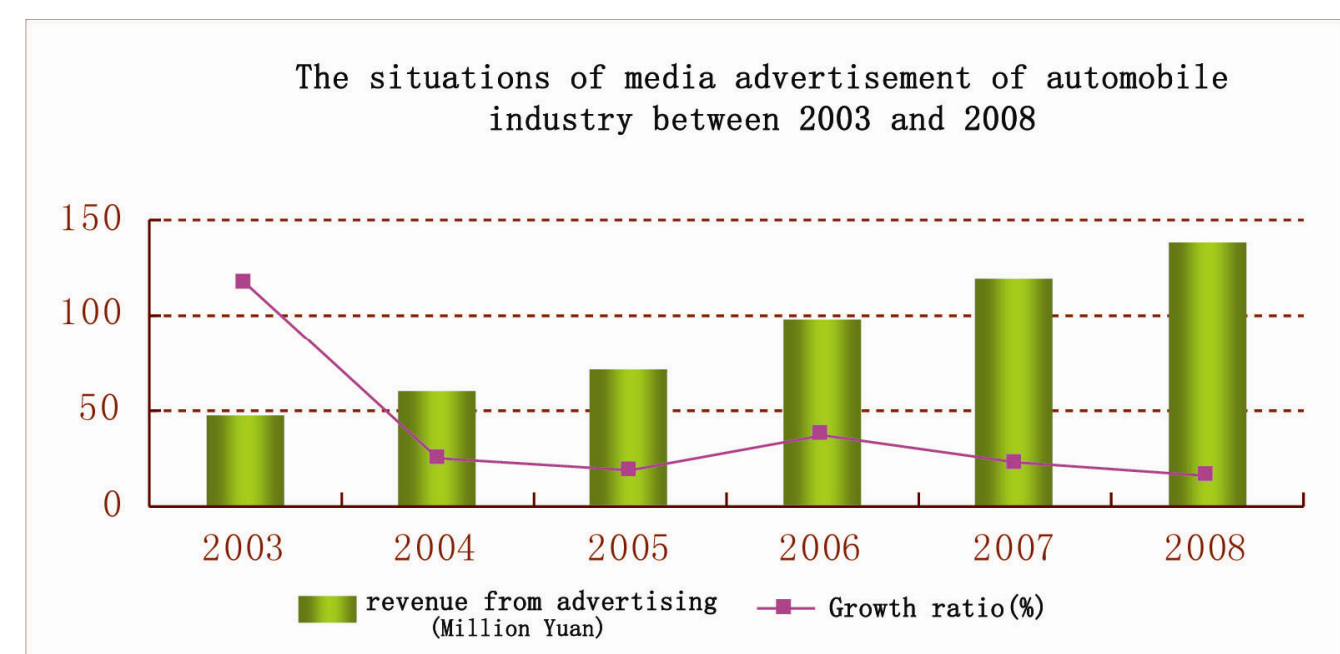

Figure 1. The situations of media advertisement of automobile industry between 2003 and 2008 Data source: State Administration of Industry and Commerce

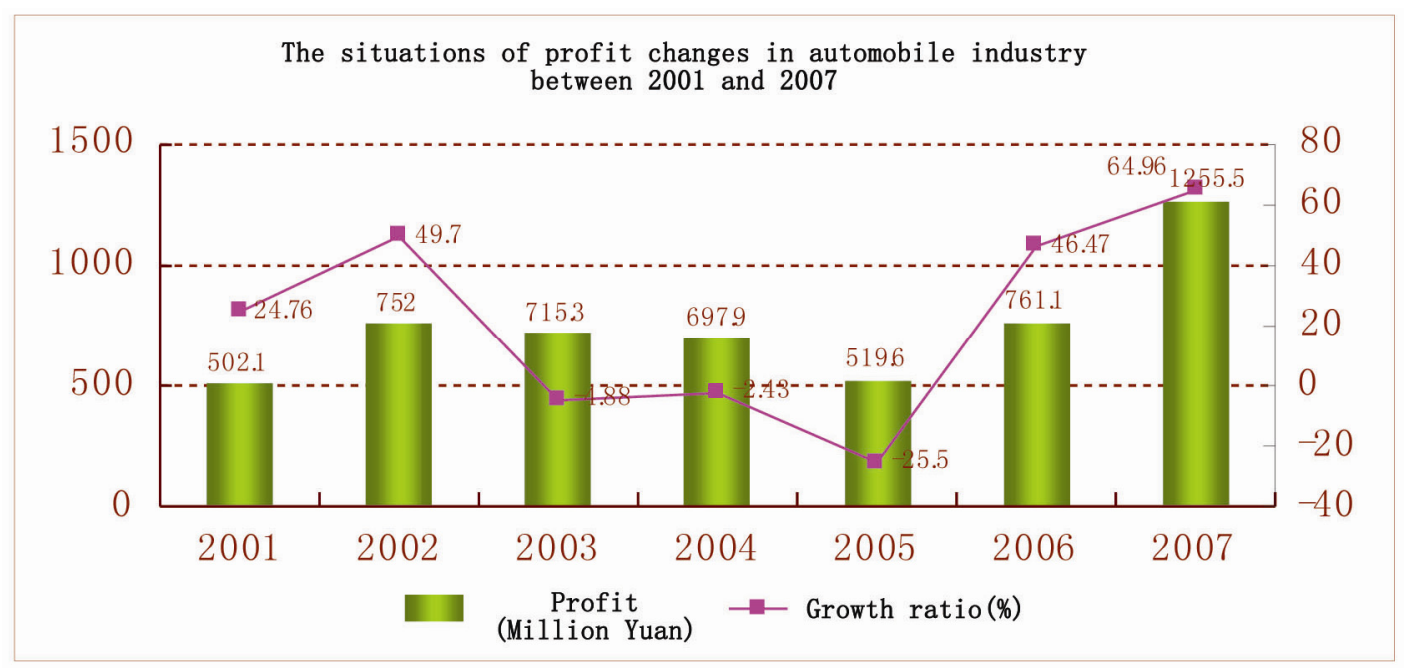

Figure 2. the situations of profit changes in automobile industry between 2001 and 2007

Data source: Year Book of Automobile Industry in 2008 